\title{
Corky, a gypsy-like retrotransposon is differentially transcribed in Quercus suber tissues
}

\author{
Margarida Rocheta*, Luísa Carvalho, Wanda Viegas and Leonor Morais-Cecílio
}

\begin{abstract}
Background: Transposable elements (TEs) make up a large part of eukaryotic genomes. Due to their repetitive nature and to the fact that they harbour regulatory signals, TEs can be responsible for chromosomal rearrangements, movement of gene sequences and evolution of gene regulation and function. Retrotransposon ubiquity raises the question about their function in genomes and most are transcriptionally inactive due to rearrangements that compromise their activity. However, the activity of TEs is currently considered to have been one of the major processes in genome evolution.

Findings: We report on the characterization of a transcriptionally active gypsy-like retrotransposon (named Corky) from Quercus suber, in a comparative and quantitative study of expression levels in different tissues and distinct developmental stages through RT-qPCR. We observed Corky's differential transcription levels in all the tissues analysed.

Conclusions: These results document that Corky's transcription levels are not constant. Nevertheless, they depend upon the developmental stage, the tissue analysed and the potential occurring events during an individuals' life span. This modulation brought upon by different developmental and environmental influences suggests an involvement of Corky in stress response and during development.
\end{abstract}

Keywords: Quercus suber, Corky, LTR retroelement, RT-qPCR, Expression

\section{Background}

Retrotransposons are generally the most abundant class of Transposable Elements (TEs), concerning their proportion in the genomes and, are widely distributed among eukaryotic genomes, especially in plants [1]. Due to their wide distribution and the diverse types of induced mutations, TEs are thought to have contributed significantly to eukaryotic genes and genomes evolution [2]. The increasing number of data obtained from genome-wide sequencing projects indicate that TEs take part in major events and are a potential pool of promoter regions for host regulatory sequences [3]. TE regulatory regions are known to be sequences of extremely rapid evolution, a characteristic of eukaryotic regulatory regions attributed to having to cope with changing genomic environments [4]. LTR-retrotransposons are 'copy-and-paste' (class I) TEs that replicate via an RNA intermediate.

\footnotetext{
* Correspondence: rocheta@isa.utl.pt

Centro de Botânica Aplicada à Agricultura (CBAA), Departamento de Recursos Naturais, Ambiente e Território, Instituto Superior de Agronomia, Universidade Técnica, de Lisboa, PORTUGAL
}

Like animal retroviruses, these retrotransposons have two LTRs, with signals for transcription initiation and termination, flanking an internal region (gag-pol) that typically contains genes and other features necessary for autonomous retrotransposition. Retrotransposon ubiquity raises the question about their function in genomes. Retrotransposon insertions in, or next to coding regions, generate mutations that can lead to changes in gene expression. For instance, Tnt $1 \mathrm{~A}$ transposition preferentially targets genic regions, suggesting that the activity of transposable elements can modulate genic functions and represent a natural source of phenotypic diversity [5]. Furthermore, run-off transcription from retrotransposons can lead to overexpression or suppression of nearby genes [6]. Transcription activity detected in several retrotransposons during certain stages of development seems to point to a potential role of these elements during plant growth $[7,8]$. Additionally, some biotic and abiotic stresses can increase transcript levels of retroelements, such as tobacco Tnt1 [9], Tto1 [10], Tto2 [11], rice's Tos17 [12] and Rtsp-1 from 
sweet potato [7]. An overall picture of retrotransposon expression is however difficult to establish due to the absence of exhaustive comparative studies in different tissues. Several Gypsy and Copia-like retroelements are known to be well represented in the Mediterranean Quercus suber $[13,14]$.

IFG7 [15] is one of the most representative Gypsy-like elements in coniferous genomes such as in several Pines [15-18] and Taxodium distichum [19], and sometimes is considered as a conifer-specific LTR retroelement [20]. However, elements like IFG7 were not yet identified in Angiosperms. In order to study the possible occurrence of a conifer derived LTR retroelement in a distant related Angiosperm tree species, as well as its potential active transcriptional activity in this species, we used IFG7 as a Gypsy representative element.

The key aims of this work were the molecular characterization of a new retrotransposon in the Quercus suber genome which is homologue to the previously identified IFG7 from Pinus radiata [15] and PpRT1 from Pinus pinaster [18] and, the quantification of its transcriptional activity in different tissues and distinct developmental stages and conditions. Together, the data presented here clearly show that this retrotransposon, named Corky, makes up a dynamic component of the cork oak genome.

\section{Findings}

\section{Organization and structure of Corky}

Corky is a gypsy retroelement that was isolated throughout genome walking in $Q$. suber genome. All generated DNA fragments were sequenced and further analysed.
The assemblage of all the sequences revealed that this retrotransposon is 5924 bp long (GeneBank: EU862277) (Figure 1a) and harbours internal regions with homology to retroviral genes gag and pol. The pol region contains sequence motifs related to the enzymes protease, reverse transcriptase, RNAseH and integrase in the same typical order known for gypsy-like retrotransposons. The complete sequence analysis reveals that the reverse transcriptase (RVT), RNaseH and integrase (INT) have the same nucleotide number as $P p R T 1$ [18] with nucleotide identity percentage of $92 \%, 96 \%$ and $95 \%$, respectively. Additionally, the HPVFH(V)S integrase motif in Corky is distinct from HLVFH(D)S found in PpRT1 and IFG7 retrotransposons. Two substitutions occurred in Corky: a leucine to a proline and an aspartic acid to a valine (Additional file 1). Changes in these motifs might be responsible for the specific targeting and insertion [21]. Flanking the 3'LTR, another region was identified as a chromatin organization modifier $(\mathrm{CH})$ [22], with 50 amino acids, which appear to play a role in the functional organization of the eukaryotic nucleus and probably targets the element to regions of high gene expression [23].

Each LTR is $333 \mathrm{bp}$ long and is flanked by a short 7 bp direct repeat 5'- CTCGATG-3' (Figure 1b), probably representing a duplication of the genomic target site produced by the insertion of a Corky copy, such as it has been reported for other retroelements [24]. Both LTRs begin and end with a 5 bp inverted repeat 5'TGTTA ...TAACA-3' including the retroviral consensus 5'TG. .CA-3'. LTRs inverted repeats are present in all retroviruses and are thought to be important for their

(a)

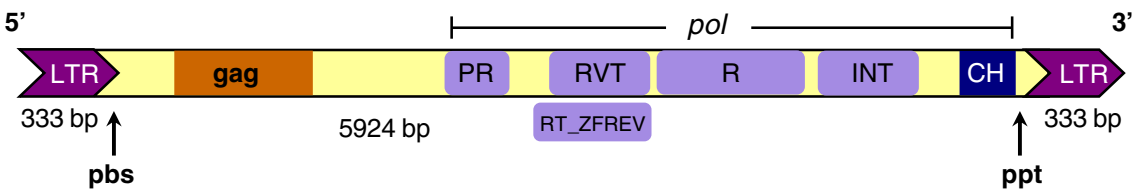

(b)

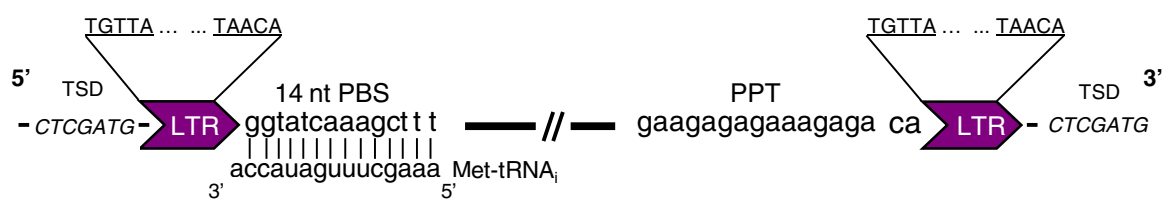

Figure 1 Organization and structure of Corky retrotransposon. (a) LTR, long terminal repeat; PR, protease; RVT, reverse transcriptase; R, RNAse H; INT, integrase; $\mathrm{CH}$, chromatin organization modifier. PBS, primer binding site. PPT, polypurine tract. The entire element has a length of 5924 bp with 333 bp LTRs. (b) The terminal boxes at each end of Corky represent LTRs. The Target Site Duplications (TSD) of 7 bp direct repeat flanking Corky is shown. Above the element, the 5 bp inverted repeats (5TGTTA... TAACA-3') within each LTR are shown in the expansions. The primer binding site (PBS) and polypurine tract (PPT) are boxed. 14 nucleotides of the $3^{\prime}$ end initiator methionine tRNA complementary to the PBS region of Corky is shown. 
integration [25] (Figure 1b). 5'LTR's Corky sequence analysis (Additional file 2) revealed two characteristic patterns of repeating motifs: one is a simple pattern of short tandem sequence motifs (a..a..) TA(G)TGATTACCCC(A)T(T)(A) and TA(T)TG(T)ATTA(TA)CCCC $(\mathrm{T}) \mathrm{T}(\mathrm{A})(\mathrm{T})$, while the other one, more complex, has two adjacent heterologous motifs (TATTGTTA, TTATATT), repeated twice as a group (ab..ab), as present within the $H I V-1$ and gypsy enhancers [26]. Both patterns are dispersed between the two TATA sequences (TATATATA) (Additional file 2). Enhancers typically consist of a series short repeated sequence motifs that are often associated with regulatory protein binding domains [27].

\section{Quantification of Corky expression}

Corky's transcription levels were monitored using the RVT and a region between the integrase and the chromodomain (Figure 2) in ten replicates of several tissues and developmental stages: embryos, root and leaf primordia (15 days after seed germination), secondary roots, old and young leaves (intact and wounded) from 2.5 year old trees and pollen grains using RT-qPCR (Figure 3).

The results obtained for both Corky regions revealed to be similar. Transcripts quantification throughout plant development, clearly demonstrated that this retroelement is always active although with significant difference between organs/cells (Figure 3 and 4). The highest Corky expression was detected in pollen, usually exposed to high levels of stress represented by an extremely low cell hydration state. High levels of expression were also detected in secondary roots (Figure 4). This situation can be interpreted in a developmental point of view, considering that the meristematic activity leading to root expansion increases the levels of Corky transcription, as it was already detected [28]. Furthermore, Corky's high levels of expression could also be due to potential wounding caused by roots growing through soil, as has also been reported for TLC1 in tomato [29] and Cire1 in sweet orange [8]. The association of Corky activity with stress is even stronger when healthy leaves are compared with those subjected to a mechanical stress similar to herbivory, increasing the number of transcripts (Figure 4). When we compared embryos, in a dormancy state, with two regions (root and leaf primordia) of the same embryo in the initial steps of germination we found high levels of transcript in the first condition, probably because in regions with high levels of cell division retrotransposon expression is not required. These results revealed that Corky expression is not only associated to stress conditions but also to different developmental stages. Taken together, these findings suggest that Corky has escaped from host silencing mechanisms and might have been preserved to a potential selective advantage.

\section{Conclusion}

Our data show good evidence that a retrotransposon (Corky) has escaped from host silencing mechanisms. The differential expression in several plant tissues in different developmental stages suggests, at least, an involvement of this retrotransposon in stress response and in developmental processes. It is likely that retroelements do not increase plasticity in an evolutionarily active way but they might play a crucial role in response to developmental/environmental challenges. Together, these results set the need to further investigate both regulation and control mechanisms that implicate retrotransposons and development.

\section{Materials and methods \\ Plant material}

Acorns of Quercus suber L. produced by open pollination and pollen used in this study were collected in a natural population at Alcácer do Sal (Portugal). The plants used in this study were obtained from those acorns and grown in the greenhouse until they were used (at 2.5 years old). Plant tissues were frozen in liquid nitrogen. Genomic DNA was extracted from samples using DNeasy ${ }^{\circledR}$ Plant Mini Kit (Qiagen ${ }^{\circledR}$ ), according to the manufacturer's instructions.

\section{Initial DNA amplification strategy}

The first set of primers [Forward- 5'ttcaactgagtcaaatttc3' and Reverse- 5'ctgtcaacccaagaaatcctcgcag 3'] (Additional file 3) used, were constructed by the assumption that the RVT sequence in $Q$. suber has sufficient similarities with the previous retrotransposon amplified in $P$. pinaster (named PpRT1) [18]. For this part of the work only DNA from young leaves was handled. A set of primers was designed to guarantee that we are in the presence of the same copy of Corky (Additional file 3). The PCR protocol consisted of the subsequent steps: an initial denaturation period at $94^{\circ} \mathrm{C}$ for 4 min., 30 cycles of

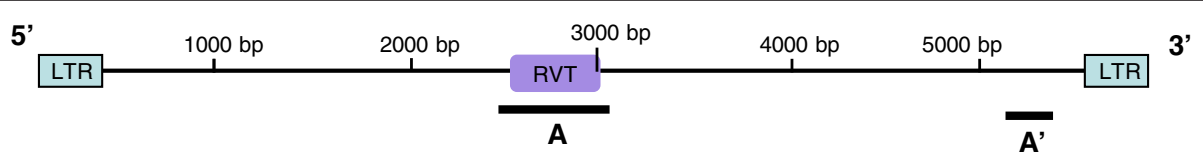

Figure 2 Fragments position in Corky element used in RT- qPCR. Real-time PCR was performed in two regions of Corky element: RVT (A) and the region between the integrase and the chromodomain $\left(\mathbf{A}^{\prime}\right)$. 


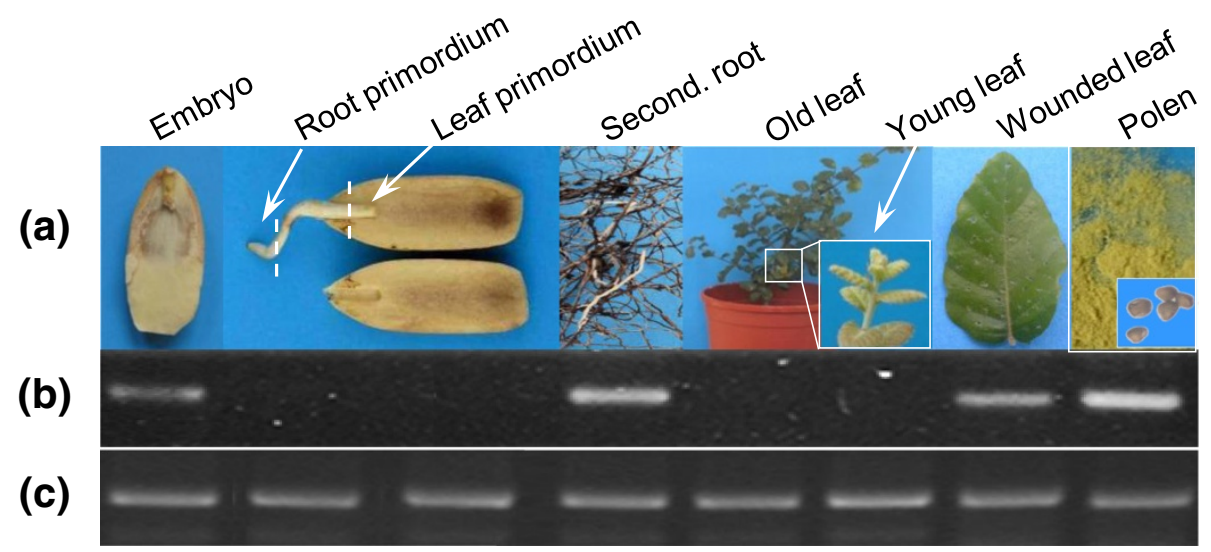

Figure 3 RT-qPCR analysis of Corky transcriptional activity. (a) Several tissues and developmental stages from Quercus suber. (b) RT-qPCR amplification of Corky RVT produced a single band of $636 \mathrm{bp}$ with different quantity levels. (c) RT-qPCR amplification of actin produced a unique band with $350 \mathrm{bp}$ and with the same intensity in all tissues.

amplification, each of which consisted of $45 \mathrm{~s}$ of denaturation at $94^{\circ} \mathrm{C}, 45 \mathrm{~s}$ of annealing at $57^{\circ} \mathrm{C}$, and $90 \mathrm{~s}$ of elongation at $72^{\circ} \mathrm{C}$ with a final elongation step of $4 \mathrm{~min}$ at $72^{\circ} \mathrm{C}$. After purification with the QIAquick ${ }^{\circledR}$ PCR purification kit, the amplified fragment was cloned using pCR 2.1-TOPO vector (Invitrogen ${ }^{\circledR}$ ) and sequenced.

\section{Genome walking}

Genome walking was performed using the Genome Walk$\mathrm{er}^{\circledR}$ kit $\left(\right.$ Clontech $\left.^{\circledR}\right)$ components according to the manufacturer's instructions. The amplification of upstream and downstream regions of RVT sequences from the libraries was performed also according to the Genome Walker ${ }^{\circledR}$

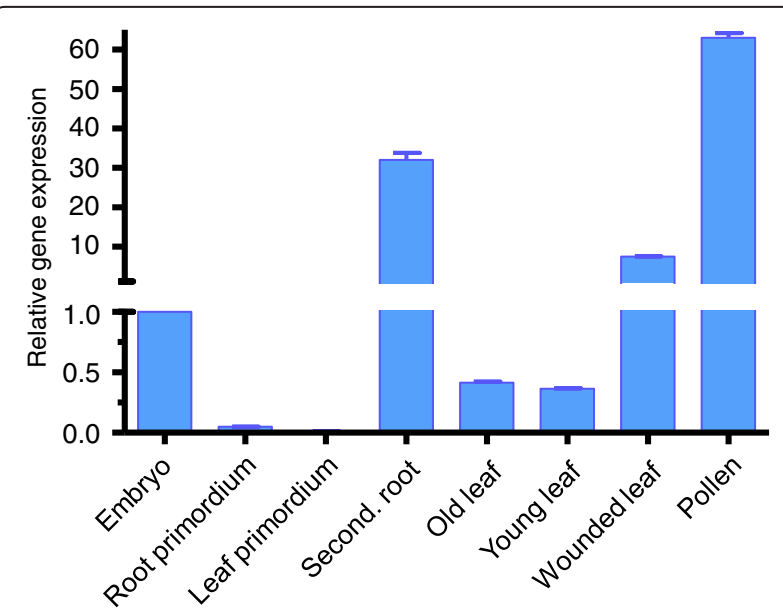

Figure 4 Relative Corky expression quantified through RT-qPCR in different tissues. mRNA was isolated from each tissue, converted to CDNA, and subjected to RT-qPCR. Relative amounts were calculated and normalized with respect to actin mRNA. Values are expressed as fold variation of each tissue type relative to the embryo (control, expression $=1$ ).
Kit protocol and the primers melting temperature (Additional file 3). All the PCR amplifications were performed with the proofreading enzyme Phusion (New England Biolabs ${ }^{\circledR}$ ). The major PCR products obtained were gel extracted by the Gel Extraction ${ }^{\circledR}$ Kit $\left(\right.$ Qiagen $^{\circledR}$ ) additionally inserted in pCR 2.1-TOPO vector ${ }^{\circledR}$ $\left(\right.$ Invitrogen ${ }^{\circledR}$ ), sequenced and aligned using the online service of National Center for Biotechnology Information (NCBI) [30]. To guarantee that all sequences belong to the same retroelement we performed numerous amplifications for the same region with different sets of primers. Additionally, primers were designed assuring that all fragments amplified overlap. Thus, all the fragments obtained were used to assemble the entire retroelement. Conversely, without other resources such as Bacterial Artificial Chromosomes (BACs), we cannot say that we have isolated the same genomic element. Although, the high overlap of the individual sequences ensures that we have got the same element, we cannot discard the hypothesis that we have reconstructed a chimeric sequence. The assembled sequence was used to search all the retrotransposon regions between both LTRs, according to the conserved motives.

\section{RNA isolation and CDNA preparation for RT-qPCR}

Total RNA was extracted from secondary roots, old leaves (one year old) and young leaves (from the year) from ten 2,5 year old plants, from ten dormant embryos, from the primordia of leaves and roots of ten germinated embryos and from ten different pollen samples, each replicate corresponding to tissue originating from one single plant and also from ten wounded leaves (leaves were pierced with a needle 240 min prior to freezing), using the RNAqueous ${ }^{\circledR}$ kit $\left(\right.$ Ambion $\left.^{\circledR}\right)$, according to the manufacturer's instructions. Nucleic acid concentration of each sample was quantified by spectrophotometry using the software Gen 5 
1.09 (Synergy HT, Bio-Tek Instruments, Winooski, USA). Total RNA quality was assessed by the $\mathrm{A}_{260} / \mathrm{A}_{280}$ and $\mathrm{A}_{260} / \mathrm{A}_{230}$. Only RNA samples with $\mathrm{A}_{260} / \mathrm{A}_{280}$ between 1.8 and 2.1 and $A_{260} / A_{230}$ between 2.0 and 2.2 were accepted for the experience. Total RNA integrity was tested through $1 \%$ agarose gel electrophoresis under denaturing conditions.

RNA samples were treated with RQ1 RNase-Free DNase (Promega, Madison, WI). cDNA was synthesized from $2 \mu \mathrm{g}$ of total RNA using random hexamers and Superscript II RNase H- reverse transcriptase (Invitrogen ${ }^{\circledR}$, Carlsbad, CA), according to the manufacturer's recommendations followed by PCR amplification using specific primers for the RVT and a region between Integrase and the chromodomain of Corky (Figure 2). As expected, amplification products were not obtained in RNA samples not yielded to reverse transcription prior to PCR. CDNA was stored at $-20^{\circ} \mathrm{C}$.

\section{Transcriptional activity of Corky}

RT-qPCR was performed in a 96 well white reaction plates (Bio-Rad ${ }^{\circledR}$, Hercules, CA), using an IQ5 Real Time PCR (Bio-Rad ${ }^{\circledR}$, Hercules, CA) with ten biological replicates and two technical replicates. For amplification specific primers corresponding to the RVT domain of Corky and a region between the Integrase and the chromodomain were used (Figure 2). Each $20 \mu \mathrm{L}$ reaction mixture well contained $10.0 \mu \mathrm{L}$ of $2 \mathrm{x}$ master mix iQ SYBR Green Supermix ${ }^{\circledR}, 2.0 \mu \mathrm{L}$ of HPLC-purified primers $(10 \mu \mathrm{M}), 7.0 \mu \mathrm{L}$ of PCR-grade $\mathrm{H}_{2} \mathrm{O}$ and $1.0 \mu \mathrm{L}$ target DNA solution. PCR amplification products were monitored via intercalation of SYBR-Green (included in the master mix). The PCR protocol consisted of an initial denaturation step at $95^{\circ} \mathrm{C}$ for $3 \mathrm{~min}, 40$ cycles of amplification, each of which consisted of $15 \mathrm{~s}$ of denaturation at $95^{\circ} \mathrm{C}, 20 \mathrm{~s}$ of annealing at $57^{\circ} \mathrm{C}$ and $50 \mathrm{~s}$ of elongation at $72^{\circ} \mathrm{C}$. As expected, amplification products were not obtained in RNA samples not subjected to the reverse transcription step prior to PCR.

To assess the primers amplification efficiency, identical volumes of cDNA samples were diluted and used to generate five-point standard curves based on a five-fold dilution series $(1 ; 1: 5 ; 1: 25 ; 1: 125 ; 1: 625)$, in triplicate. Amplification efficiency $(E)$ is calculated as $E=10^{(-1 / a)}-1$, "a" being the slope of the linear regression curve $(y=a$ $\log (x)+b)$ fitted over the log-transformed data of the input cDNA dilution (y) plotted against the respective quantification cycle $(\mathrm{Cq})$ values $(\mathrm{x})$. E-values of the target genes were considered comparable when they did not exceed $100 \pm 10 \%$, corresponding to a standard curve slope of $3.3 \pm 0.33$. All cDNA samples were diluted 50 fold and were amplified in duplicate in two independent PCR runs.
To generate a baseline-subtracted plot of the logarithmic increase in fluorescence signal $(\Delta R n)$ versus cycle number, baseline data were collected between the cycles 5 and 17. All amplification plots were analysed with an $R_{n}$ threshold of 0.2 , at the beginning of the region of exponential amplification, to obtain $\mathrm{Cq}$ and the data obtained were exported into a MS Excel workbook (Microsoft ${ }^{\circledR}$ Inc.) for further analysis. In order to compare data from different PCR runs or cDNA samples, $\mathrm{C}_{\mathrm{q}}$ values were normalized to the $C_{q}$ value of actin, a housekeeping gene expressed at a relatively high and constant level [31]. Gene expression was calculated using the $\Delta \Delta \mathrm{C}_{\mathrm{q}}$ method [32]. Results are expressed as fold variation of each tissue relative to each of the other.

\section{Additional files}

Additional file 1: Structural features of Corky retrotransposon. Conserved amino acid (single letter code) domains of Reverse

Transcriptase (underline), RNaseH, Integrase (underline) and Chromo (underline). In the Reverse Transcriptase two important motives PFGL and DDILIYS are in red. In RNaseH the CDAS motif is pointed in bold. In the integrase the three subdomains are in red: $\mathrm{HH}-\mathrm{CC} ; \mathrm{D}, \mathrm{DE}$ and $\mathrm{G}-(\mathrm{D} / \mathrm{E})-\mathrm{X}_{10-}$ $\left.\left.20-K L-X_{2} / R / K\right)-F / Y M\right)-X-G-P-(F / Y)-X-(I / N)$. The HPVFH(V)S motif is showed in bold.

Additional file 2: Nucleotide sequence of the 5' LTR from Corky. The repeating sequences motifs are underlined and the two TATA box sequences are boxed.

Additional file 3: Primers used to amplify Corky.

\section{Abbreviations}

$C_{q}$ : threshold cycle; bp: base pairs; nt: nucleotides; RT-qPCR: reverse transcription real time PCR; TE: transposable element; RVT: reverse transcriptase.

\section{Competing interests}

The authors declare that they have no conflict of interest.

\section{Authors' contributions}

$M R$ and LM conceived the experiments; MR and LC performed the experiments; MR, LM and LC analysed the data and wrote the manuscript; WV commented the manuscript. All authors read and approved the manuscript.

\section{Acknowledgments}

We thank "Fundação para a Ciência e Tecnologia" for the post-doc grant SFRH/BPD/5707/2001 to L.C., for post-doc grant SFRH/BPD/64905/2009 to M. R. and for the "Plurianual" funding to CBAA and PTDC/AGR-GFL/104197/2008. We are extremely grateful to Sara Amâncio for the cheer encouragement and helpful suggestions. We also give our thanks' Quirina Santos-Costa for the English revision.

Received: 18 March 2012 Accepted: 2 August 2012

Published: 13 August 2012

\section{References}

1. Hua-Van A, Rouzic AL, Maisonhaute C, Capy C: Abundance, distribution and dynamics of retrotransposable elements and transposons: similarities and differences. Cytogenet Genome Res 2005, 110:426-440.

2. Kazazian HH: Mobile elements: drivers of genome evolution. Science 2004, 303:1626-1632.

3. Fablet M, Souames S, Biémont C, Vieira C: Evolutionary pathways of the tirant LTR retrotransposon in the Drosophila melanogaster subgroup of species. J Mol Evol 2007, 64:438-447. 
4. Ludwig MZ, Bergman C, Patel NH, Kreitman M: Evidence for stabilizing selection in a eukaryotic enhancer element. Nature 2000, 403:564-567.

5. Grandbastien MA, Audeon CE, Bonnivard JM, Casacuberta B, Chalhoub APP, Costa QH, Lea D, Melayah M, Petit C, Poncet SM, et al: Stress activation and genomic impact of Tnt1 retrotransposons in Solanaceae. Cytogenet Genome Res 2005, 110:229-241.

6. Kashkush K, Feldman M, Levy AA: Transcriptional activation of retrotransposons alters the expression of adjacent genes in wheat. Nat Genet 2003, 33:102-106.

7. Tahara M, Aoki T, Suzuka S, Yamashita H, Tanaka M, Matsunaga S, Kokumai S: Isolation of an active element from a high-copy-number family of retrotransposons in the sweetpotato genome Mol Genet Genomics 2004, 272:116-127.

8. Rico-Cabanas L, Martínez-Izquierdo JA: Cire1, a novel transcriptionally active Ty1-copia retrotransposon from Citrus sinensis. Mol Genet Genomics 2007, 277:365-377.

9. Beguiristain T: Grandbastien MA, Puigdomenech P, Casacuberta JM: Three Tnt 1 subfamilies show different stress-associated patterns of expression in tobacco. Consequences for retrotransposon control and evolution in plants. Plant Physiol 2001, 127:212-221.

10. Takeda S, Sugimoto K, Otsuki H, Hirochika H: A 13-bp cis-regulatory element in the LTR promotor of the tobacco retrotransposob Tto1 is involved in responsiveness to tissue culture, wounding, methyl jasmonate and fungal elicitors. Plant J 1999, 18:383-393.

11. Hirochika H: Activation of tobacco retrotransposons during tissue culture. Embo J 1993, 12:2521-2528.

12. Hirochika H, Sugimoto $\mathrm{K}$, Otsuki $Y$, Tsugawa $H$, Kanda M: Retrotransposons of rice involved in mutations induced by tissue culture. Proc Natl Acad SCi USA 1996, 93:7783-7788.

13. Alves S, Ribeiro T, Inácio V, Rocheta M, Morais-Cecílio L: Genomic organization and dynamics of repetitive DNA sequences in representatives of three Fagaceae genera. Genome 2012, 55:348-359.

14. Carvalho M, Ribeiro T, Viegas W, Morais-Cecílio L, Rocheta M: Presence of env-like sequences in Quercus suber retrotransposons. J Appl Genet 2010, 51:461-467.

15. Kossack DS, Kinlaw CS: IFG, a gypsy-like retrotransposon in Pinus (Pinaceae), has an extensive history in pines. Plant Mol Biol 1999, 39:417426.

16. Kovach A, Wegrzyn JL, Parra G, Holt C, Bruening GE, Loopstra CA, Hartigan J, Yandell M, Langley $\mathrm{CH}$, Korf I, et al: The Pinus taeda genome is characterized by diverse and highly diverged repetitive sequences. BMC Genomics 2010, 11:420

17. Magbanua ZV, Ozkan S, Bartlett BD, Chouvarine P, Saski CA, Liston A, Cronn RC, Nelson CD: Peterson DG. Adventures in the enormous: A 1.8 million clone BAC library for the $21.7 \mathrm{~Gb}$ genome of loblolly pine. PLoS One 2011, 6:16214.

18. Rocheta M, Cordeiro J, Oliveira M, Miguel C: PpRT1: the first complete gypsy-like retrotransposon isolated in Pinus pinaster. Planta 2006, 225:551-562.

19. Liu WTS, Sehgal S, Chouvarine P, Peterson D: Characterization of the genome of bald cypress. BMC Genomics 2011, 12:553.

20. Kovach AWJ, Parra G, Holt C, Bruening GE, Loopstra CA, Hartigan J, Yandell M, Langley CH, Korf I, Neale DB: The Pinus taeda genome is characterized by diverse and highly diverged repetitive sequences. BMC Genomics 2010, 11:420.

21. Singleton TL: Levin. $\mathrm{HL}$ : A long terminal repeat retrotransposon of fission yeast has strong preferences for specific sites of insertion. Eukaryot Cell 2002, 1:44-55.

22. Lynch C, Tristem M: A co-opted gypsy-type LTR-retrotransposon is conserved in the genomes of humans, sheep, mice, and rats. Curr Biol 2003, 13:1518-1523.

23. Eissenberg JC: Molecular biology of the chromo domain: an ancient chromatin module comes of age. Gene 2001, 275:19-29.

24. Konieczny A, Voytas DF, Cummingst MP, Ausubel FM: A superfamily of Arabidopsis thaliana retrotransposons. Genetics 1991, 127:801-809.

25. Hindmarsh P, Leis J: Retroviral DNA integration. Microbiol Mol Biol Rev 1999, 63:836-843.

26. McDonald JF, Matyunina LV, Wilson S, Jordan IK, Bowen NJ, Miller WJ: LTR retrotransposons and the evolution of eukaryotic enhancers. Genetica 1997, 100:3-13.

27. Atchison ML: Enhancers: mechanism of action and cell specificity. Annu Rev Cell Biol 1998, 4:127-153.
28. Vicient $\mathrm{CM}$ : Transcriptional activity of transposable elements in maize. BMC Genomics 2010, 11:601.

29. Tapia G, Verdugo I, Yañez M, Ahumada I, Theoduloz C, Cordero C, Poblete F, González E: Ruiz-Lara S. Involvement of ethylene in stress-induced expression of the TLC1.1 retrotransposon from Lycopersicon chilense Dun. Plant Physiol 2005, 138:2075-2086.

30. Altschul SF, Gish W, Miller W, Myers EW, Lipman DJ: Basic local alignment search tool. J Mol Biol 1990, 215:403-410.

31. Kim BR, Nam HY, Kim SU, Kim SI, Chang YJ: Normalization of reverse transcription quantitative-PCR with housekeeping genes in rice. Biotechnol Lett 2003, 25:1869-1872.

32. Livak KJ, Schmittgen TD: Analysis of relative gene expression data using real-time quantitative $\mathrm{PCR}$ and the $2^{-\mathrm{DD}} \mathrm{C}_{\mathrm{T}}$ method. Methods 2001, 25:402-408

doi:10.1186/1756-0500-5-432

Cite this article as: Rocheta et al:: Corky, a gypsy-like retrotransposon is differentially transcribed in Quercus suber tissues. BMC Research Notes 2012 5:432

\section{Submit your next manuscript to BioMed Central and take full advantage of:}

- Convenient online submission

- Thorough peer review

- No space constraints or color figure charges

- Immediate publication on acceptance

- Inclusion in PubMed, CAS, Scopus and Google Scholar

- Research which is freely available for redistribution 